Fourth International Conference on Sustainable Construction Materials and Technologies

http://www.claisse.info/Proceedings.htm

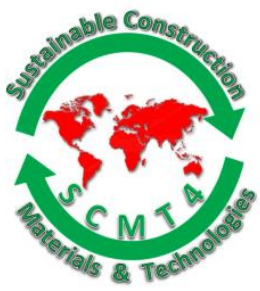

SCMT4

Las Vegas, USA, August 7-11, 2016

\title{
Development of Alkali Activated Slag-Fly Ash Mortars: Mix Design and Performance Assessment
}

\author{
X. Gao ${ }^{1 \mathrm{a}}$, Q.L. Yu ${ }^{1 \mathrm{~b}}$, and H.J.H. Brouwers ${ }^{1 \mathrm{c}}$ \\ ${ }^{1}$ Department of the Built Environment, Eindhoven University of Technology, P.O. Box 513, 5600 \\ $M B$ Eindhoven, the Netherlands, \\ ${ }^{1 a}$ Email: <X.Gao@tue.nl>, ${ }^{1 b}$ Email:<Q.Yu@bwk.tue.nl>,, ${ }^{1 c}$ Email:<jos.brouwers@tue.nl>.
}

\begin{abstract}
In this paper, alkali activated slag-fly ash mortars were prepared by applying the modified Andreasen \& Andersen particle packing model in order to maximize the packing of the granular solid materials. The effects of two key manufacturing factors: slag/fly ash ratio and activator modulus, on the fresh behaviors, gel structure development, compressive strength, and drying shrinkage were investigated. The results show that a large variation of slump flow can be found when different combinations of slag/fly ash ratio and activator modulus were used. The microstructure analysis carried out by FTIR and TG shows that the gel structure remains stable after $1 \mathrm{~d}$ of curing, mixes with higher slag content and lower activator modulus show a slightly higher bound water content. The main reaction product is a chain structured C-A-S-H type gel regardless of the slag/fly ash ratio and activator modulus, but a slightly higher main absorption band is shown in samples with high fly ash content. A higher content of slag in the slag-fly ash mix leads to a higher strength in general. An optimum activator modulus of 1.4 in terms of strength appears in all cases. Both slag content and activator modulus strongly affect the drying shrinkage, and using high amount of fly ash and low activator modulus can effectively reduce the drying shrinkage.
\end{abstract}

\section{INTRODUCTION}

Alkali activated materials (AAM) have been extensively studied in recent years due to their lower environmental impacts compared to ordinary Portland cement (OPC) and superior performances. Based on the chemical composition of the raw materials, alkali activated materials can be classified into two types: calcium and silica enriched $(\mathrm{Ca}+\mathrm{Si})$ system and aluminosilicates dominated $(\mathrm{Si}+\mathrm{Al})$ systems $[\mathrm{Li}$ et al. 2010]. The typical precursor of calcium enriched system is ground granulated blast furnace slag, having a tobermorite-like $\mathrm{C}-\mathrm{A}-\mathrm{S}-\mathrm{H}$ gel with a low $\mathrm{Ca} / \mathrm{Si}$ ratio and a high $\mathrm{Al}$ content as major reaction product [Brough and Atkinson 2002]. The represented materials of $\mathrm{Si}+\mathrm{Al}$ systems are class $\mathrm{F}$ fly ash or metakaolin, having three-dimensional N-A-S-H type gels as the major products [Granizo et al. 2002]. Recently, growing interests have been paid to blended alkali systems that are prepared by mixing high calcium contained materials with low calcium aluminosilicates, since the blended binder system exhibits modified properties regarding setting times, workability, shrinkage, mechanical properties and durability compared to the individual ones [Lee 2013]. The structure of the reaction products in the blended system is mainly depending on the activator type and dosage, raw materials composition and curing conditions. Micro-scale 
investigations identified that the reaction products are generally stably coexisting C-(A)-S-H and N-A-S-H type gels with high amounts of cross-linking [Ismail et al. 2014]; also the large amount of available calcium and aluminate affect the original structure of N-A-S-H and C-(A)-S-H gels, respectively [García et al. 2009]. The recent achievements in understanding the blended alkali systems provide solid theoretical support for the further researches; also those modified properties demonstrate a promising future for the application of alkali activated materials.

On the other hand, it is commonly accepted that an optimal packing of granular ingredients is the key for achieving excellent mechanical strength and durable structures, and several mix design methods have been proposed in cement based system such as the Linear Packing Density Model, Solid Suspension Model and Compressive Packing Model [Larrard and Sedran 2002]. Among those design methodologies, the modified Andreasen \& Andersen particle packing model, which is based on the integral particle size distribution approach of continuously graded mixes, shows conveniences by considering fine particles into the design process. While presently, when designing the recipes of alkali activated blended mortars and concretes, key manufacturing parameters from the aspects of activator and raw material are the main concerns, while to the authors' knowledge limited attention has been paid to the packing of the granular ingredients. It is possible that by giving additional consideration to the particle packing in the mix design stage, the binders in alkali activated system will be used in a more efficient manner, while certain fresh and hardened properties may also improve as a result.

Another important issue of alkali activated materials is the shrinkage, since it is well linked to the cracking tendency and consequently the durability related properties. The previous investigations revealed that the alkali activated high calcium system usually exhibits a higher degree of drying shrinkage than the cement based system [Melo et al. 2008], while the alkali low calcium systems can show a lower value than OPC. It was also concluded the activator type and content, the physicochemical properties of the raw material and curing conditions are the key factors that affect the shrinkage behaviors [Shi 1996]. However, there still exists very limited study about the relationships between key synthesizing factors and the shrinkage in alkali activated blended systems. In overall, the objective of this study is to design the room temperature cured alkali activated slag-fly ash blended mortars by applying the modified Andreasen \& Andersen particle packing model; while the effects of key synthesizing factors on fresh behaviors, gel structure development, strength and drying shrinkage of the mortars specimens are investigated.

\section{EXPERIMENTAL INVESTIGATION}

\section{Materials}

The solid precursors used in this study were ground granulated blast furnace slag (GGBS, provided by ENCI B.V., the Netherlands) and a commercial Class F fly ash. Their major chemical compositions were analyzed by X-ray fluorescence and are shown in Table 1. Besides, limestone powder was used as filler while a micro sand (0-1 mm, provided by Graniet-Import Benelux B.V., the Netherlands) and a normal sand $(0-2 \mathrm{~mm})$ were used as fine aggregates. The the detailed particle size distributions of all solid materials are given in Figure 1. Concerning the alkaline activators, a mixture of sodium hydroxide (pellets, analytical level of 99 wt. \%) and commercial sodium silicate solution $\left(27.69 \% \mathrm{SiO}_{2}, 8.39 \% \mathrm{Na}_{2} \mathrm{O}\right.$ and $63.92 \% \mathrm{H}_{2} \mathrm{O}$ by mass) was used. The desired activator modulus ( $\mathrm{Ms}, \mathrm{SiO}_{2} / \mathrm{Na}_{2} \mathrm{O}$ molar ratio) was achieved by adding the appropriate amount of sodium hydroxide into the sodium silicate solution. Distilled water was added in order to reach the desired water/binder ratio. The mixed activator solution was cooled down to room temperature for $24 \mathrm{~h}$ before further use. 
Table 1. Major Chemical Composition of Slag and Fly Ash.

\begin{tabular}{|c|c|c|}
\hline Oxides (wt.\%) & FA & GGBS \\
\hline $\mathrm{SiO}_{2}$ & 54.62 & 34.44 \\
\hline $\mathrm{Al}_{2} \mathrm{O}_{3}$ & 24.42 & 13.31 \\
\hline $\mathrm{CaO}$ & 4.44 & 37.42 \\
\hline $\mathrm{MgO}$ & 1.43 & 9.89 \\
\hline $\mathrm{Fe}_{2} \mathrm{O}_{3}$ & 7.21 & 0.47 \\
\hline $\mathrm{Na}_{2} \mathrm{O}$ & 0.73 & 0.34 \\
\hline $\mathrm{K}_{2} \mathrm{O}$ & 1.75 & 0.47 \\
\hline $\mathrm{SO}_{3}$ & 0.46 & 1.23 \\
\hline $\mathrm{LO}$ & 2.80 & 1.65 \\
\hline
\end{tabular}

Mix design methodology. The mixes of alkali activated slag-fly ash mortars were designed using the modified Andreasen and Andersen (A\&A) model in order to maximize the packing of the granular solid materials:

$P(D)=\frac{D^{q}-D_{\min }^{q}}{D_{\max }^{q}-D_{\min }^{q}}$

where $P(D)$ is a fraction of the total solids materials that are smaller than the particle size $D(\mu m)$, Dmax is the maximum particle size $(\mu \mathrm{m})$, Dmin is the minimum particle size $(\mu \mathrm{m})$ and $\mathrm{q}$ is the distribution modulus. The distribution modulus (q) in the modified A\&A model is used to determine the proportion between the fine and coarse particles in the mixture. The value of q is fixed at 0.23 for all mixtures in this study, based on previous experiences. The proportions of each individual material in the mix are adjusted until an optimum fit between the composed mix grading curve and the target curve is reached, using an optimization algorithm based on the Least Squares Method (LSM), namely the deviation between the target curve and the composed mix expressed by the sum of the squares of the residuals (RSS) at defined particle sizes is minimal [Hüsken and Brouwers 2008]. Therefore, the optimized mixture will possess a compact matrix due to the optimal packing. An example of the detailed mix designs based on the modified Andreasen \& Andersen particle packing model is shown in Figure 1. It should be noted that this mix design methodology is based on the volumetric fractions of all used materials, including both solids and liquids. In Portland cement system, the liquid component is primarily water; while in the case of alkali activated system, the liquid (activator) consists of water, dissolved $\mathrm{NaOH}$ and sodium silicates. Based on the fact that both $\mathrm{NaOH}$ and the silicates in waterglass are well dissolved in the activator solution, their effect on the solids' packing is not taken into account in this study; while the densities of the liquid activator are calculated based on each individual mix and applied in the packing model.

Sample preparation. The activator used in this study has an equivalent sodium oxide content of $5 \%$ by mass of the binder and activator moduli of 1.0, 1.4 and 1.8. The target activator modulus was reached by mixing sodium silicate solution and sodium hydroxide pellets with a solution/pellets mass ratio of 3.82 , 6.41 and 10.27, respectively. The water/powder ratio was kept constant as 0.4 in all mixtures. The water consisted of the added distilled water and the water contained in the activator solution. Slag/fly ash ratios of 80/20,60/40 and 40/60 by mass were used. All mortar specimens were prepared in a laboratory mixer; firstly the solid precursors were added into the mixer and mixed for $1 \mathrm{~min}$, followed by the activating solution; the ingredients were mixed at a slow speed for $30 \mathrm{~s}$ and rested for $30 \mathrm{~s}$ before another $120 \mathrm{~s}$ at a medium speed. Then the fine fillers and aggregates were added and another $120 \mathrm{~s}$ of mixing was performed. The fresh mortar was then poured into plastic molds of $40 \times 40 \times 160 \mathrm{~mm}^{3}$ and vibrated for $1 \mathrm{~min}$, covered with a plastic film on the top surface for $24 \mathrm{~h}$; finally all specimens were demolded and cured at a temperature of $20^{\circ} \mathrm{C}$ and a relative humidity of $95 \%$ until their testing age. 


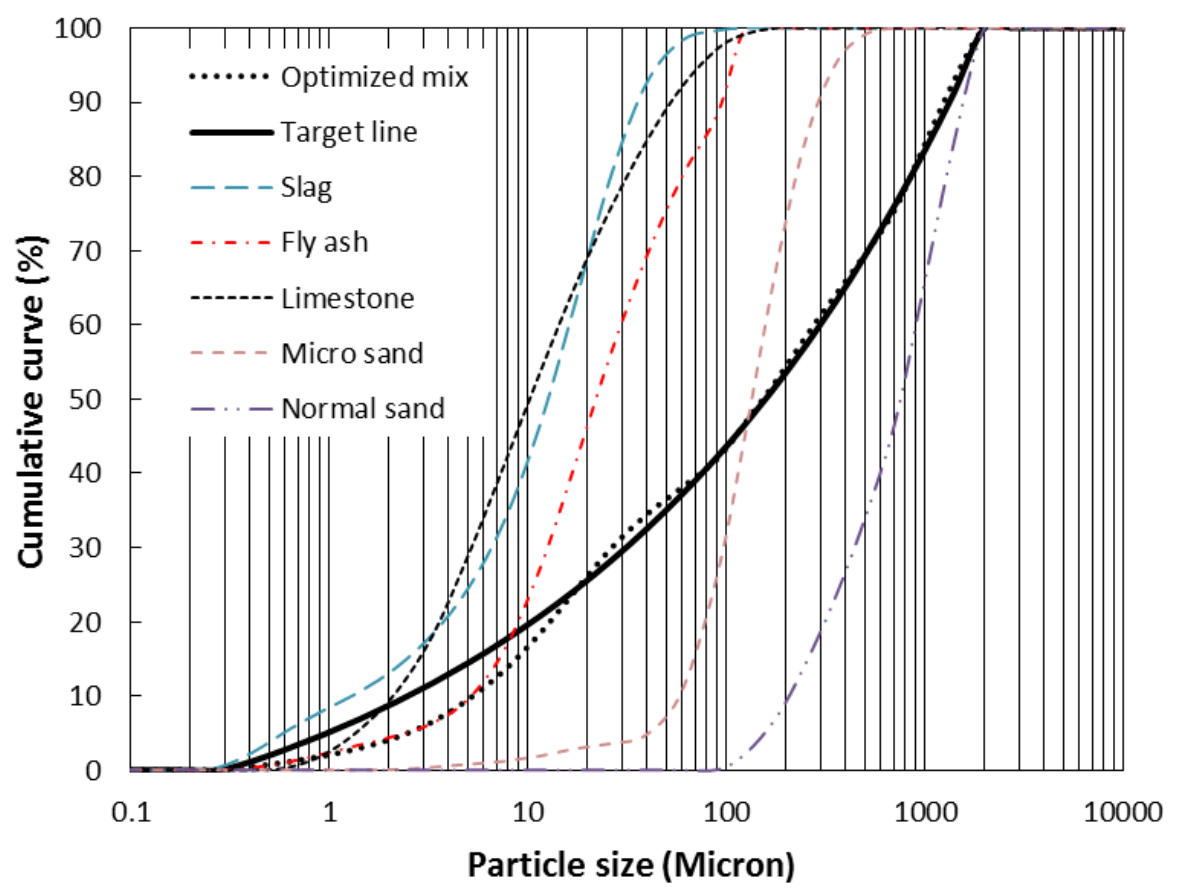

\section{Figure 1. Particle Size Distributions of Raw Materials, Target Curve and Resulting Integral Grading Line of a Sample Mix.}

Testing methods. The workability of mortar samples were tested by the mini spread-flow test according to EN 1015-3. Fresh samples were transferred into a standard conical ring and a free flow without jolting was allowed. Fourier transform infrared spectroscopy measurements were performed in a Varian 3100 instrument with the wavenumbers ranging from 4000 to $600 \mathrm{~cm}^{-1}$ at a resolution of $1 \mathrm{~cm}^{-1}$. The thermogravimetric (TG) analyze were conducted by using a STA 449 F1 instrument, samples were heated up to $1000{ }^{\circ} \mathrm{C}$ at a rate of $5^{\circ} \mathrm{C} / \mathrm{min}$ with nitrogen as protective gas. Both FTIR and TG analysis were carried out at the age of 1,7 and $28 \mathrm{~d}$, respectively. The compressive strength testing was carried out according to EN 196-1. The samples for drying shrinkage test were cast in molds with dimensions of $40 \times 40 \times 160 \mathrm{~mm}^{3}$ and cured in sealed condition at a temperature of $20^{\circ} \mathrm{C}$. After $24 \mathrm{~h}$ of curing, specimens were exposed in a cabinet with a temperature of $20^{\circ} \mathrm{C}$ and relative humidity of $50 \%$, also the initial length $\left(\mathrm{L}_{0}\right)$ was measured at that time. Afterwards, the length $\left(\mathrm{L}_{\mathrm{n}}\right)$ was measured once per day until the age of $28 \mathrm{~d}$.

\section{RESULTS AND DISCUSSION}

Flowability. The slump flows of the fresh alkali activated slag-fly ash mortars are presented in Figure 2. It can be seen that the activator modulus exhibits a more significant effect on the slump flow than slag/fly ash ratio in general. For instance, in samples with a constant activator modulus of 1.0, the slump flow increases from 17.5 to $19.3 \mathrm{~cm}$ when shifting the slag/fly ash ratio from 80/20 to 40/60. Similar results are also shown in mixes with other activator moduli. This can be simply explained by the different water demand between slag and fly ash that is caused by their morphology differences, where slag usually presents a more angular particle shape and larger surface area. On the other hand, compared to the effect of slag/fly ash ratio, a higher range of flowability is shown in samples with a different activator modulus. For a fixed slag/fly ash ratio of $80 / 20$, when increasing the activator modulus from 1.0 to 1.4 and then 1.8 , the slump flow is increased from $17.5 \mathrm{~cm}$ to $24.1 \mathrm{~cm}$ and $27.0 \mathrm{~cm}$. Dramatic increases in slump flow are also found in samples with other slag/fly ash ratios. One possible explanation for the higher influence of the activator 
modulus on flowability is that the additional provided silicate from activator benefits the workability due to the nature of the silicate groups, since higher activator modulus means a higher proportion of sodium silicate in the activator solution. Activator with lower modulus usually exhibits a more intensive reaction at early stages, it is possible that a faster dissolution of the raw materials increases the viscosity of the fresh mortars and results in a reduced slump flow.

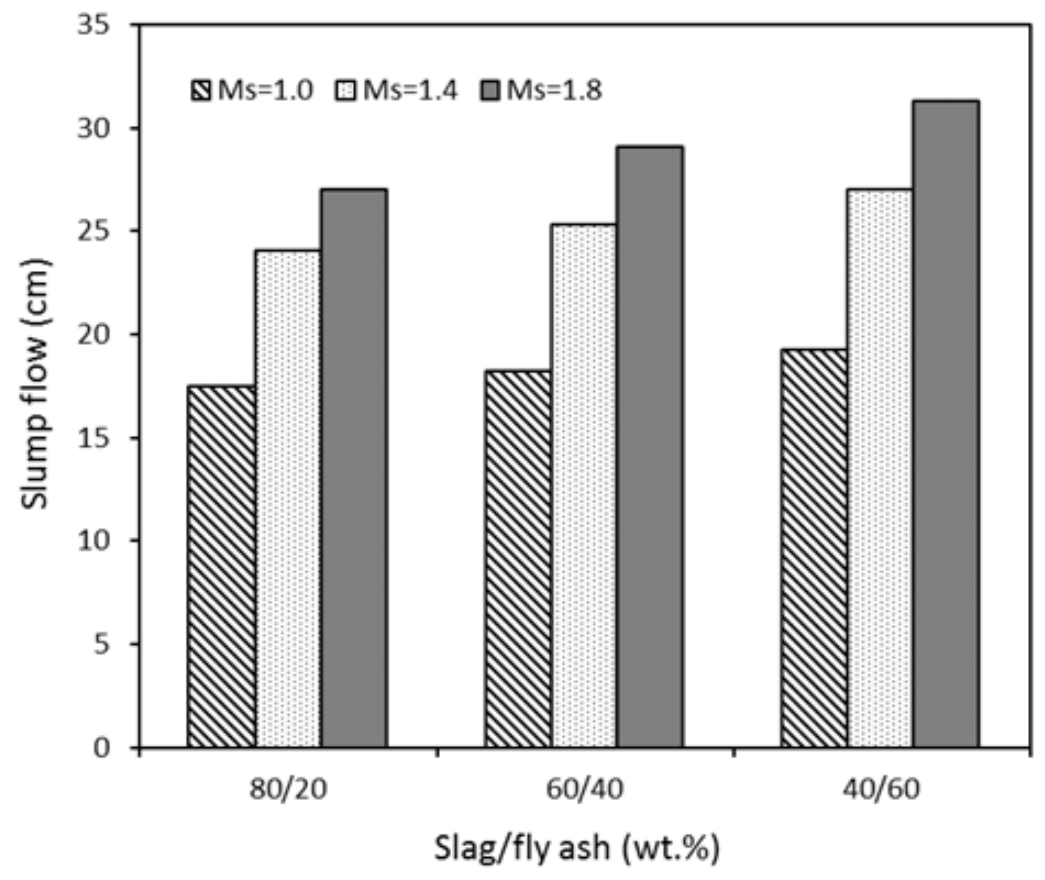

Figure 2. Slump Flow of AA Slag-Fly Ash Mortars.

FTIR analysis. The infrared spectra of the unreacted slag and fly ash are given in Figure 3. It is clear that the original slag shows a main vibration band that is located around $900 \mathrm{~cm}^{-1}$, which is due to the asymmetric stretching vibration of terminal Si-O bonds; and a small shoulder at around $670 \mathrm{~cm}^{-1}$ indicates the stretching vibration of tetrahedral T-O groups. As for the fly ash, the main absorption band is shown at around 1020 $\mathrm{cm}^{-1}$, demonstrating that the structure is dominated by the bridge Si-O-T bonds; while some weak absorption bands that are located around 1080, and 600 to $800 \mathrm{~cm}^{-1}$ manifest the presence of small amount of quartz and mullite [Criado et al. 2007]. The difference in the main absorption band is attributed to the structural differences of the amorphous phase within the raw materials. The mixture with a slag/fly ash ratios of 40/60 and activator modulus 1.0 was chosen to study the reaction products, since all mixtures present very similar results. After one day of activation, a main absorption band at around $940 \mathrm{~cm}^{-1}$ is presented, which is assigned to the asymmetric stretching vibration of the non-bridging $\mathrm{Si}-\mathrm{O}$ bonds. It indicates that the reaction product is dominated by chain structures rather than highly polymerized one. Compared to the starting materials, the main absorption band shows an increase from 900 to $940 \mathrm{~cm}^{-1}$ for the slag, indicating that the $\mathrm{Si}-\mathrm{O}$ networks experienced a certain degree of polymerization; while for the fly ash, the main absorption band shifts from $1020 \mathrm{~cm}^{-1}$ to lower numbers, implying the breakdown of the original high cross-linked bridging $\mathrm{Si}-\mathrm{O}$ bonds and the polymerization process of the aluminosilicates did not take place in this blended system. All mixtures also exhibit a slight shoulder at around $875 \mathrm{~cm}^{-1}$, this absorption band together with the one at $1400 \mathrm{~cm}^{-1}$ are assigned to the vibrations of O-C-O in carbonates. Since there is no carbonate source within the raw materials, it is highly probable that a certain extent of carbonation may have occurred during the reaction or curing process. The vibration bands at $1640 \mathrm{~cm}^{-1}$ and around $3200 \mathrm{~cm}^{-1}$ (not shown in the figure) in all mixes manifest the presence of bound water within the reaction products. The water observed here may include both physically and chemically bound ones. 


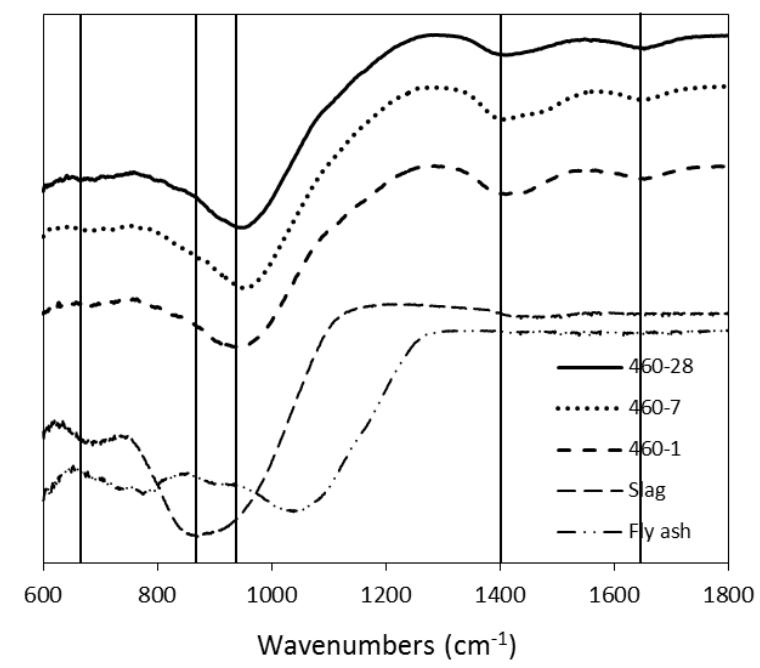

Figure 3. FTIR Spectra of Starting Materials and Reaction Products

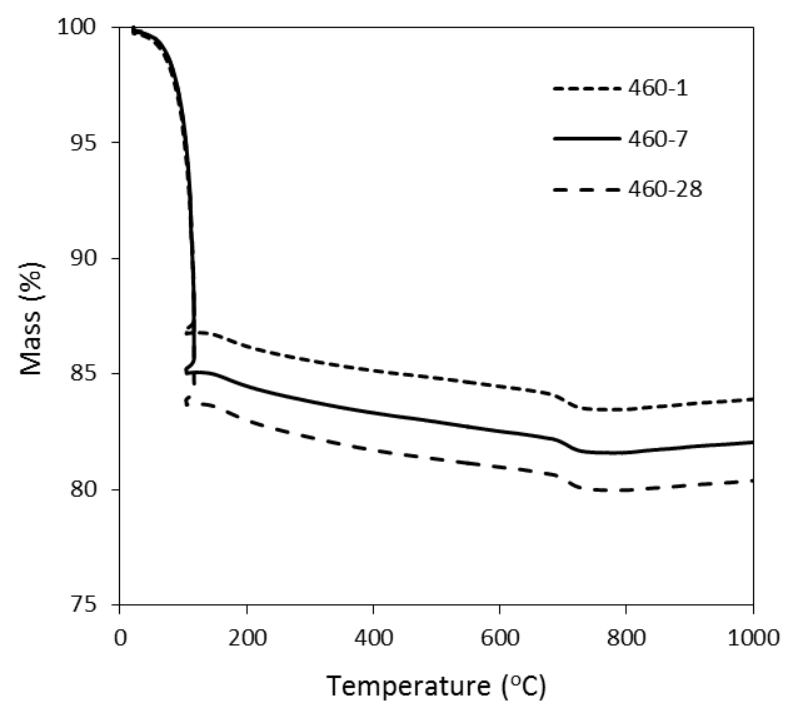

Figure 4. TG Analyses of AA Slag-Fly Ash Blends at 1, 7 and $28 \mathrm{~d}$.

TG analysis. Figure 4 depicts the thermogravimetry results of pastes with slag/fly ash ratio of 40/60 and activator modulus of 1.0 and at the age of 1,7 and 28 days, respectively. It is clear that a significant mass loss before around $110{ }^{\circ} \mathrm{C}$ is shown in all mixes; this is mainly attributed to the loss of physically bound water within the matrix. The mixture presents a negligible mass loss between around $105{ }^{\circ} \mathrm{C}$ and $150{ }^{\circ} \mathrm{C}$, followed by a gradual decrease until heated to around $700{ }^{\circ} \mathrm{C}$. The continuous mass loss after around $150{ }^{\circ} \mathrm{C}$ is generally regarded as the loss of chemically bound water due to the gradual decomposition of the reaction products. Between around $700{ }^{\circ} \mathrm{C}$ and $1000{ }^{\circ} \mathrm{C}$, only a very slight and moderate mass loss is shown in general. Considering no other abrupt mass losses are shown between $105{ }^{\circ} \mathrm{C}$ and $1000{ }^{\circ} \mathrm{C}$, it can be concluded that the reaction products are mainly amorphous gels with bound water. To be specific, the physically bound water content is $13.2 \%$ after $1 \mathrm{~d}$ of curing, and this value slightly increases to $15.0 \%$ at 7 $\mathrm{d}$ and $16.3 \%$ at $28 \mathrm{~d}$. Similarly, the mass loss between around $105{ }^{\circ} \mathrm{C}$ and $1000{ }^{\circ} \mathrm{C}$ also shows a small increment as a function of time, which increases from $2.9 \%$ to $3.3 \%$ between 1 and $28 \mathrm{~d}$. It should be noted 
that the mass loss within this temperature range is not only due to the loss of chemically bound water from decomposed gels; the decomposition of the carbonates also plays a role. This is confirmed by the relatively remarkable mass loss between $600{ }^{\circ} \mathrm{C}$ and $800{ }^{\circ} \mathrm{C}$, and the presence of carbonates observed in the FTIR results in this study. The slightly increased chemically bound water content after $1 \mathrm{~d}$ of curing suggests that the main reaction process may have already completed within the first day of curing, and the reaction at later ages present detectable but limited contribution. Previous researches on the early age reaction kinetics also confirmed the completion of the main reactions during the first few hours [Gao et al. 2015]. Combined with the FTIR results, it is reasonable to conclude that the slightly increased chemically bound water after $1 \mathrm{~d}$ is mainly attributed to the continuous formation of C-A-S-H type gels in a small scale, rather than generating new phases.

Compressive strength. The 7 and $28 \mathrm{~d}$ compressive strength of mortars with different activator moduli and slag/fly ash ratios are depicted in Figure 5. Generally, the samples exhibit compressive strengths that range from 52.8 MPa to $68.4 \mathrm{MPa}$ at $7 \mathrm{~d}$, and $67.4 \mathrm{MPa}$ to $86.4 \mathrm{MPa}$ after $28 \mathrm{~d}$ of curing. Besides, samples with higher slag contents show a relatively high strength and a medium activator modulus of 1.4 presents the optimum compressive strength in every case. Specifically, for mixes with a slag/fly ash ratio of 80/20, the $7 \mathrm{~d}$ strength is $61.8 \mathrm{MPa}$ with an activator modulus of 1.0 , and it increases to $68.4 \mathrm{MPa}$ when increasing the activator modulus to 1.4 , a further increase of the modulus to 1.8 leads to a reduction of strength to 65.3 $\mathrm{MPa}$. Similar tendency is also shown at $28 \mathrm{~d}$, samples with an activator modulus of 1.4 exhibits the highest strength of 86.4 MPa; while both mixes with lower or higher activator moduli show a lower compressive strength: 79.5 MPa and 82.6 MPa, respectively. The presence of the optimal activator modulus implies that within the parameter ranges in this study, both too high or too low activator moduli may present a negative influence on strength.

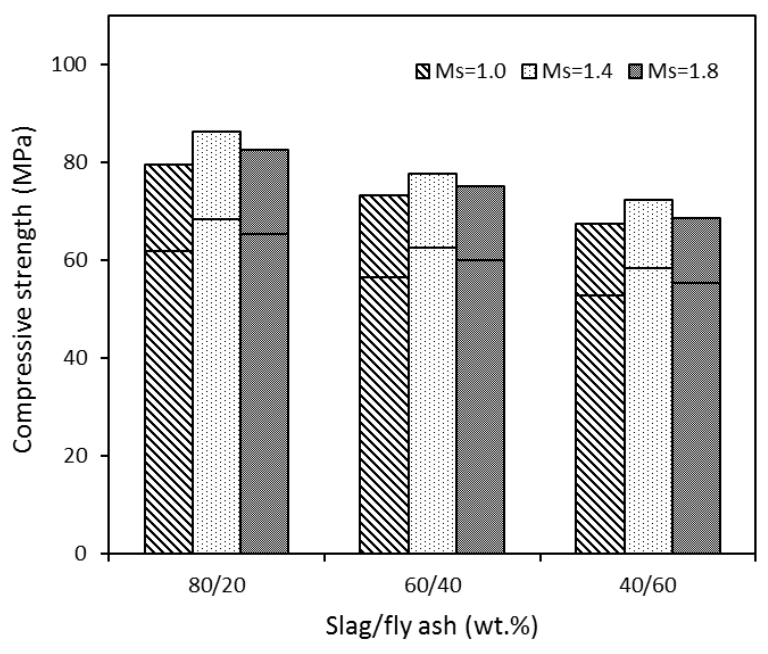

Figure 5. 7 and 28 d Compressive Strength of AA Slag-Fly Ash Mortars.

Concerning the effect of raw materials' composition, there is a gradual decrease in compressive strength when lowering the slag/fly ash ratio. As shown in Figure 5 that for a constant activator modulus of 1.4, the $7 \mathrm{~d}$ compressive strength for mixes with slag/fly ash ratio of $80 / 20$ is $68.4 \mathrm{MPa}$, which slightly decreases to 62.6 MPa and 58.4 MPa when lowering the slag content to $60 \%$ and $40 \%$, respectively. The corresponding $28 \mathrm{~d}$ strength also decreases from 86.4 MPa to 77.8 MPa and 72.3 MPa, respectively. The beneficial effect is mainly due to its higher reactivity than fly ash under ambient temperature, and the higher content of network-modifying cations in slag leads to the formation of reaction products with more C-A-S-H type gels. Then a higher strength is presented as a consequence. 
Drying shrinkage. The drying shrinkage of samples with slag/fly ash ratios of 80/20 and 40/60 are presented in Figure 6. It can be seen that all mixes exhibit an obvious length change over time. As shown in Figure 6, samples with a lower slag content and a lower activator modulus show a lower drying shrinkage in general. For example, with a constant slag/fly ash ratio of 80/20, the length change at the age of $28 \mathrm{~d}$ is around $-3364 \times 10^{-6}$ for mixes with an activator modulus of 1.0 , while this value increases to $-3996 \times 10^{-6}$ and $-4864 \times 10^{-6}$ when increasing the modulus to 1.4 and 1.8 , respectively. Similarly, when shifting the activator modulus from 1.0 to 1.8 , the length change is increased by $29.1 \%$ and $71.3 \%$ in samples with a slag/fly ash ratio of 40/60 at $28 \mathrm{~d}$. Thus it is clear that a significant increase of drying shrinkage will result when increasing the activator modulus. This is in agreement with the previous study on the drying shrinkage of alkali activated slag-fly ash blends that the higher extra silicate content from the activator is, the higher drying shrinkage is [Ma and Ye 2015]. In addition, the result also implies that using activators with a lower modulus can effectively reduce the drying shrinkage to some extent. A significant reduction of drying shrinkage is presented when a lower slag content is used in the slag-fly ash blends. It can be seen that with a constant activator modulus, taking 1.4 as an example, the $28 \mathrm{~d}$ length change is $-3996 \times 10^{-6}$ for mixtures with a slag/fly ash ratio of $80 / 20$; while it decreases to $-2797 \times 10^{-6}$ when lowering the slag/fly ratio to $40 / 60$, suggesting that replacing slag by fly ash is an ideal approach to reduce the dry shrinkage. In overall, both the incorporation of fly ash into slag and lowering the silicate content from activator are efficient methods of reducing the shrinkage.

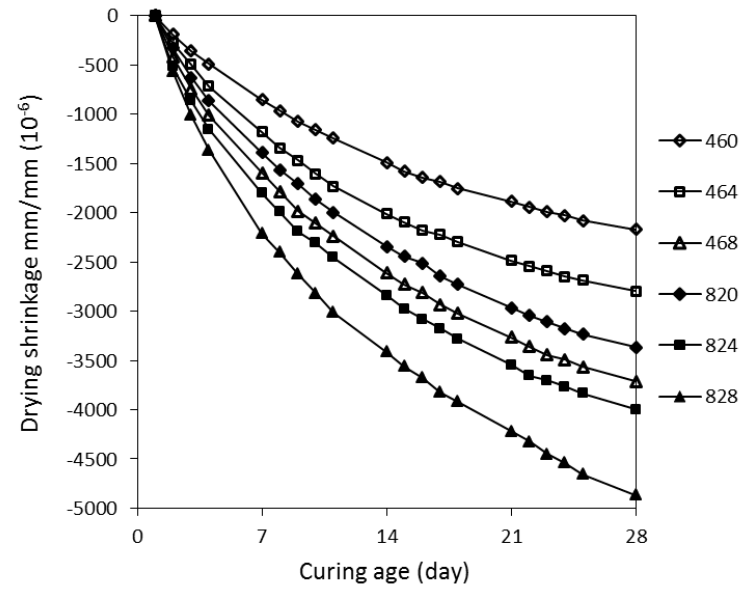

Figure 6. Drying shrinkage of AA slag-fly ash mortars.

\section{CONCLUSION}

The following brief conclusions can be drawn based on the experimental results:

- A large range of slump flow can be caused by both slag/fly ash ratio and activator modulus, and the activator modulus exhibits a more considerable effect.

- The main reaction product is a C-A-S-H type gel, and it remains stable after $1 \mathrm{~d}$ of curing, slight gel development is still observed at later ages.

- A higher compressive strength is observed in samples with higher slag contents; and an optimum strength is shown in mixtures with an activator modulus of 1.4 in all cases.

- Both raw materials' composition and activator modulus show remarkable influence on the shrinkage behavior. The incorporation of fly ash into slag can effectively reduce the shrinkage of mortar samples; also the drying shrinkage can be reduced to certain extent by decreasing the additional silicate content from the activator. 


\section{ACKNOWLEDGEMENT}

This research was supported by China Scholarship Council and the Department of the Built Environment at Eindhoven University of Technology. The authors gratefully thank Mr. P. de Vries (ENCI B.V., the Netherlands) and Mr. J. van Eijk (Knauf Insulation, the Netherlands) for the materials supply. Furthermore, the authors wish to express their gratitude to the following sponsors of the Building Materials research group at TU Eindhoven: Rijkswaterstaat Grote Projecten en Onderhoud; Graniet-Import Benelux; Kijlstra Betonmortel; Struyk Verwo; Attero; Enci; Rijkswaterstaat Zee en Delta-District Noord; Van Gansewinkel Minerals; BTE; V.d. Bosch Beton; Selor; GMB; Geochem Research; Icopal; BN International; Eltomation; Knauf Gips; Hess AAC Systems; Kronos; Joma; CRH Europe Sustainable Concrete Centre; Cement \& Beton Centrum; Heros and Inashco (in chronological order of joining).

\section{REFERENCES}

Brough, AR, Atkinson A. (2002). "Sodium silicate-based alkali-activated slag mortars: Part I. Strength, hydration and microstructure." Cem Concr Res, 32, 865-79.

Criado M, Fernandez-Jimenez A, Palomo A (2007). "Alkali activation of fly ash: Effect of the $\mathrm{SiO}_{2} / \mathrm{Na}_{2} \mathrm{O}$ ratio Part I: FTIR study.” Microporous Mesoporous Mater, 106:180-91.

De Larrard F, Sedran T. (2002). "Mixture-proportioning of high-performance concrete." Cem Concr Res, 32:1699-704.

Gao X, Yu QL, Brouwers HJH. (2015). "Reaction kinetics, gel character and strength of ambient temperature cured alkali activated slag-fly ash blends." Constr Build Mater, 80:105-115.

García-Lodeiro I, Macphee DE, Palomo A, Fernández-Jiménez A. (2009). "Effect of alkalis on fresh C-SH gels. FTIR analysis." Cem Concr Res, 39:147-53.

Granizo ML, Alonso S, Blanco-Varela MT, Palomo A (2002). "Alkaline activation of metakaolin: effect of calcium hydroxide in the products of reaction." J Am Ceram Soc, 85(1):225-31.

Hüsken G, Brouwers HJH. (2008). "A new mix design concept for earth-moist concrete: a theoretical and experimental study." Cem Concr Res, 38:1246-59.

Ismail I, Bernal SA, Provis JL, Nicolas RS, Hamdan S, Deventer JSJ. (2014). "Modification of phase evolution in alkali-activated blast furnace slag by the incorporation of fly ash". Cem Concr Compos, 45:125-35.

Lee NK, Lee HK (2013). "Setting and mechanical properties of alkali-activated fly ash/slag concrete manufactured at room temperature." Constr Build Mater, 47:1201-9.

Li C, Sun HH, Li LT. (2010). "The comparison between alkali-activated slag ( $\mathrm{Si}+\mathrm{Ca}$ ) and metakaolin ( $\mathrm{Si}+\mathrm{Al})$ cements." Cem Concr Res, 40:1341-49.

Ma Y, Ye G. (2015). "The shrinkage of alkali activated fly ash.” Cem Concr Res, 368:75-82.

Melo Neto AA, Cincotto MA, Repette W. (2008). "Drying and autogenous shrinkage of pastes and mortars with activated slag cement." Cem Concr Res, 38:565-74.

Shi C. (1996). "Strength, pore structure and permeability of alkali-activated slag mortars." Cem Concr Res, 26:1789-9. 